\title{
The temperature dependent current-voltage characteristics of chemically prepared AL/(P)PBS Schottky barrier junction
}

\author{
L. Rajen Singh ${ }^{\mathrm{a}, *}$, M. A. Hussain ${ }^{\mathrm{b}}$ \\ ${ }^{a}$ Department of Physics, D. M. College of Science, Imphal-795001, Manipur, \\ India \\ ${ }^{b}$ Department of Physics, Imphal College, Impha-795130, Manipur, India
}

\begin{abstract}
Zinc $(\mathrm{Zn})$ doped nanocrystalline lead sulphide $(\mathrm{PbS})$ thin film is prepared by chemical bath deposition (CBD) method at bath deposition temperature 313K using Zinc Acetate, Lead Acetate and Thiourea. The prepared films is characterized by X-ray diffraction (XRD), energy dispersive X-ray analysis (EDX), Scanning electron microscopy (SEM) and transmission electron microscopy (TEM) analysis. $\mathrm{Al} /(\mathrm{p}) \mathrm{PbS}$ Schottky barrier junctions are fabricated onto indium tin oxide (ITO) substrate to study the junction parameters. The Current-Voltage $(I-V)$ characteristics of the junctions is measure in the temperature range of 303 to $333 \mathrm{~K}$ and various junction parameters are calculated. The ideality factor $(\mathrm{n})$ and Schottky barrier height $\left(\phi_{b}\right)$ at different temperatures are found to vary from 5.31 to 4.47 and $0.749 \mathrm{eV}$ to $0.755 \mathrm{eV}$ respectively. The carrier concentration is determined from the capacitance-voltage $(C-V)$ plot and found to be of the order $10^{16} \mathrm{~cm}^{-3}$.
\end{abstract}

(Received November 4, 2021; Accepted February 19, 2022)

Keywords: Nanocrystalline, Thin film, Schottky barrier junctions, Ideality factor, Schottky barrier height

\section{Introduction}

Semiconducting materials are used in different solid state devices depending on their optical and electrical properties. The metal-semiconductor junctions are used as rectifiers, microwave diodes, UV detectors, switching diodes, photo sensors and solar cells [1-7]. Among the semiconductors compound, $\mathrm{PbS}$ is a narrow band gap semiconductor compound having a optical band gap of $0.41 \mathrm{eV}$ in bulk form [8]. The energy band gap $\left(E_{g}\right)$ of the nanocrystalline $\mathrm{PbS}$ compound can be tuned to anywhere between $0.41 \mathrm{eV}$ (bulk) to $4 \mathrm{eV}$ [9]. For these reasons, many researchers have study this material by various deposition techniques such as spray pyrolysis [10], electro deposition [11, 12], microwave heating [13,14], successive ionic layer adsorption and reaction (SILAR) [15], vacuum evaporation [16], molecular beam epitaxy [17], chemical bath deposition [18-21] etc. Among the various techniques, chemical bath deposition method have several advantages as compared to other techniques such as uniform film deposition, inexpensive, convenient for large area deposition and do not require sophisticated instruments [22,23]. The dimensions of the crystallites and quality of the films can be controlled by varying the deposition parameters such as $\mathrm{pH}$ value, reaction time, deposition temperature, concentration of lead, Zinc and sulphur ions. The deposition conditions and techniques play a major role in the physical properties of $\mathrm{Zn}$ doped $\mathrm{PbS}$ thin films.

Metal-Semiconductor (MS) contacts are the most widely used rectifying contacts in the electronics industry [24-26]. The performance and reliability of a Schottky diode is drastically influenced by the interface quality between the deposited metal and semiconductor surface [27]. The detailed measurements of the physical parameters of the Schottky barrier formed at the interface of a semiconducting colloidal quantum dot film and a metal and the ideality factor 1.3 for the Al/PbS CQD Schottky devices were reported by Clifford et al. [28]. Debnath et al. [29] have reported a ITO/PbS CQD film/LIF/Metal Schottky device with fill factor 51\% and efficiency

\footnotetext{
* Corresponding author: 1_rajen03@yahoo.com https://doi.org/10.15251/CL.2022.192.131
} 
3.6\%. Strasfeld et al.[30] fabricated planar PbS quantum dot devices with ohmic and Schottky type electrodes and investigated the vast difference between the local photocurrents that arise due to Ohmic and Schottky contacts. However, there is very few literatures available on the properties of $\mathrm{Al} /(\mathrm{p}) \mathrm{PbS}$ Schotty junctions fabricated by CBD. Therefore, our main aim in this work is to study the structural and surface morphological characteristics of $\mathrm{Zn}$ doped $\mathrm{PbS}$ films and currentvoltage characterization of $\mathrm{Al} /(\mathrm{p}) \mathrm{PbS}$ Schottky junction.

\section{Experimental details}

Zinc doped nanocrystalline $\mathrm{PbS}$ thin film is deposited onto chemically cleaned glass substrates and ITO glass substrates by CBD method using Zinc acetate, lead acetate and thiourea as $\mathrm{Zn}^{+2}, \mathrm{~Pb}^{+2}$ and $\mathrm{S}^{-2}$ sources respectively. For this, freshly prepared $0.2 \mathrm{M}$ solution of lead acetate (premixed with $4 \mathrm{wt}$. \% Zinc acetate) and $\mathrm{pH}$ value of the solution was maintained at 11 by drop wise addition of $\mathrm{NH}_{3}$ solution. Another equal amount of $0.2 \mathrm{M}$ solution of thiourea was added and the solution mixture was stirred well. Bare glass substrates and ITO glass substrates are immersed vertically into the solution. The mixture solution is heated at $313 \mathrm{~K}$ for 1 hour and then kept at room temperature for $24 \mathrm{hr}$ for further deposition. After deposition, the substrates coated with $\mathrm{Zn}$ doped $\mathrm{PbS}$ on both sides are taken out and thoroughly washed with distilled water and dried in air. The films deposited on the glass substrates are used for XRD, EDX, SEM and TEM studies. The structural characterization of the film is obtained by using X-ray diffraction (XRD) XPERT-PRO Philips diffractometer. Surface morphology of the film is studied using JEOL-JSM 6360. Transmission electron microscopy (TEM) of the $\mathrm{Zn}$ doped PbS sample is carried out using JEM2100 to estimate particle size. Semiconductor-metal contacts are made by evaporating gold electrodes of area ( $2 \mathrm{~mm} \times 2 \mathrm{~mm}$ ) on the $\mathrm{Zn}$ doped $\mathrm{PbS}$ films deposited over ITO glass substrates as shown in Fig.5 (inset). A Schottky junction device in the configuration $\mathrm{Al} /(\mathrm{p}) \mathrm{PbS} / \mathrm{ITO}$ was thus, obtained to study junction parameters. $I-V$ characteristics in the temperature range $303-333 \mathrm{~K}$ were measured by using Keithley Electrometer (6514) and Rishabh multimeter (14S). The temperature on the sample surface was measured by Instron (IN-303) digital temperature controller using PT100 sensor. $C-V$ measurement was carried out using Systronics LCR-Q meter (928). The type of the $\mathrm{Zn}$ doped $\mathrm{PbS}$ semiconductor as found by hot probe method was p-type. For forward bias, the negative terminal of the voltage source is connected to the ITO glass while the positive terminal to the gold electrodes.

\section{Results and discussion}

\subsection{Structural properties}

The XRD patterns of nanocrystalline $\mathrm{Zn}$ doped $\mathrm{PbS}$ thin films deposited on the glass substrates are shown in Fig. 1. The diffraction peaks observed at $2 \theta$ values of $25.826^{\circ}, 29.736^{\circ}$, $42.892^{\circ}$ and $50.773^{\circ}$ correspond to (111), (200), (220) and (311) planes respectively which are in good agreement with the JCPDS data reference code no. 01-077-0244 [31]. Therefore, it has been concluded that the deposited $\mathrm{PbS}$ thin films are polycrystalline in nature with cubic structure. The orientation of the grain growth is preferably along (200) direction. The preferential orientation in the (200) direction has also been reported by Gadave et al. [32] for PbS films deposited by CBD at $80^{\circ} \mathrm{C}$ and by Puiso et al. [33] of SILAR deposited PbS films on Si substrates. The average crystallite size is calculated using Scherer's equation [34]

$$
D=\frac{0.94 \lambda}{\beta \cos \theta}
$$

where $k$ is a constant equal to $0.94, \lambda$ is the wavelength of the $\mathrm{x}$-ray used $\left(\mathrm{CuK}_{\alpha}\right.$ radiation, $\lambda=$ $1.5418 \AA$ ), $\beta$ is the full width at half maximum (FWHM) of the dominant $x$-ray diffraction peak in 
radian and $\theta$ is the diffraction angle of the dominant peak. The average crystallite size of the $\mathrm{Zn}$ doped $\mathrm{PbS}$ was found to be $15 \mathrm{~nm}$.

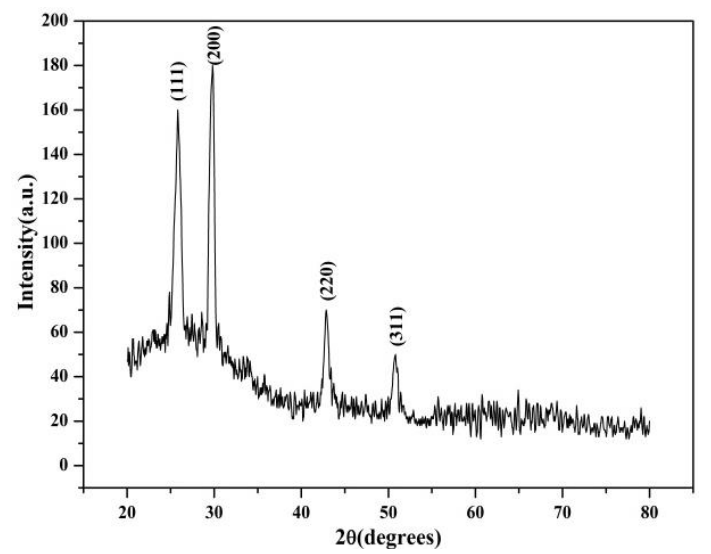

Fig. 1. XRD spectra of nanocrystalline Zn doped PbS thin film.

\subsection{Elemental analysis}

To confirm the chemical composition of $\mathrm{Zn}$ doped $\mathrm{PbS}$ thin film, the elemental analysis of the samples were performed by Energy Dispersive X-ray Spectrometer (EDX). Fig. 2 shows a typical EDX spectrum of $4 \mathrm{wt} . \% \mathrm{Zn}$ doped $\mathrm{PbS}$ thin film. The spectrum confirms that $\mathrm{Pb}, \mathrm{S}$ and $\mathrm{Zn}$ atoms are present in the prepared film. The average atomic percentage of $\mathrm{Pb}, \mathrm{S}$ and $\mathrm{Mn}$ are found to be 49.24, 54.98 and 5.78 respectively. The presence of $\mathrm{Zn}$ atoms in the spectra indicates that $\mathrm{Zn}$ atoms are incorporated with the PbS film. The extra peaks observed in the EDAX spectra correspond to some impurity elements like $\mathrm{Mg}, \mathrm{Si}, \mathrm{Na}, \mathrm{Ca}$ which are due to glass substrate or the substrate holder used in the EDAX instrument [35-37]. These might also be due to presence of C and $\mathrm{O}$ due to exposure of the film to the atmosphere [38]. There is no source of these elements in the chemicals used for the $\mathrm{Zn}$ doped $\mathrm{PbS}$ film synthesis. We consider only the atomic $\%$ of $\mathrm{Pb}, \mathrm{S}$ and $\mathrm{Zn}$ present in the spectra of doped sample neglecting the percentage of the other elements present in the spectra.

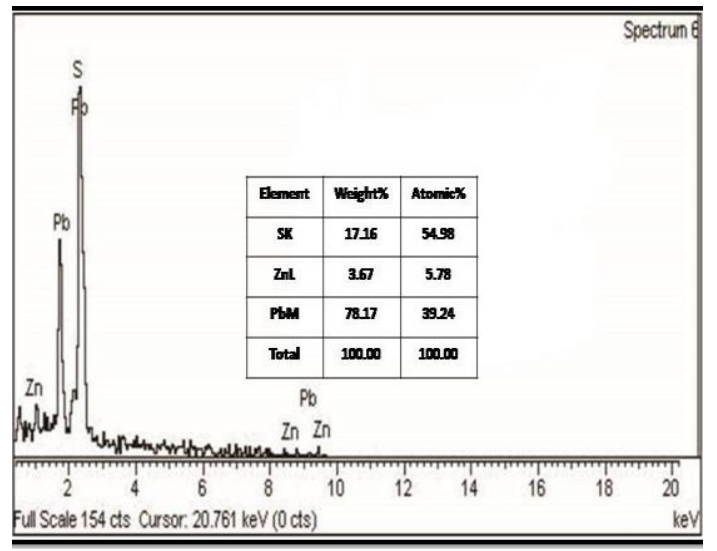

Fig. 2. EDAX spectra of $4 \mathrm{wt} . \% \mathrm{Zn}$ doped $\mathrm{PbS}$ thin prepared at concentration $0.2 \mathrm{M}$, pH value 11 and deposition temperature $313 \mathrm{~K}$.

\subsection{SEM and TEM studies}

The surface morphology of nanocrystalline $\mathrm{Zn}$ doped $\mathrm{PbS}$ thin films based on SEM image analysis is shown in Fig. 3. It is observed that the film is dense, smooth, homogeneous without any pore and consisting of grains of unequal shapes and sizes. 


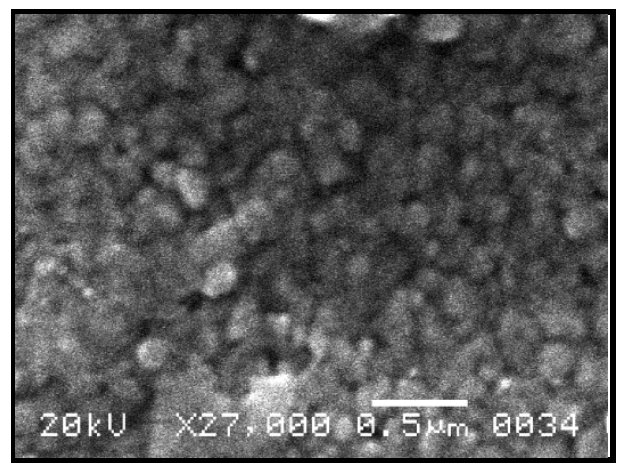

Fig. 3. SEM Photograph of nanocrystalline Zn doped PbS thin film.
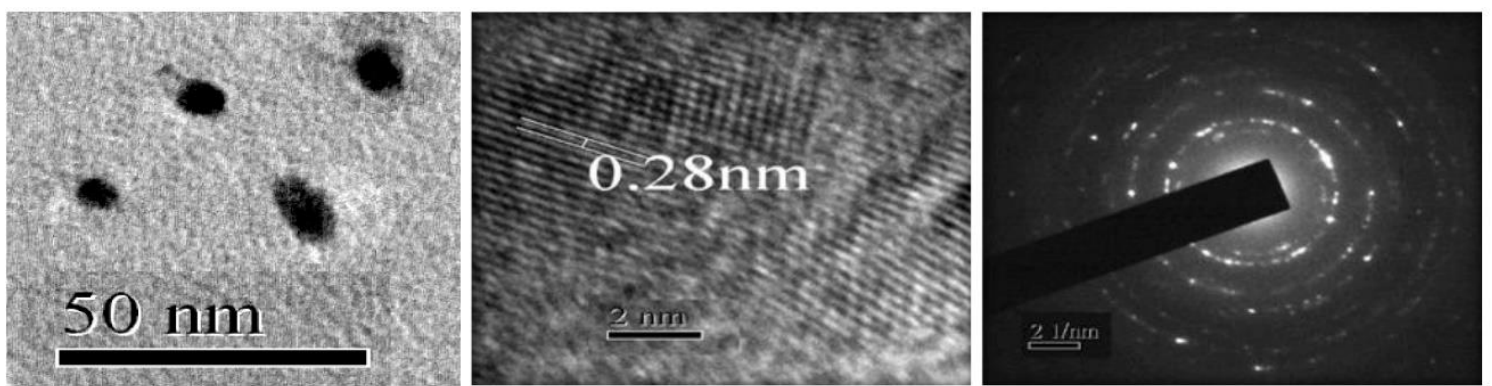

Fig. 4. (a) TEM image (b) High-resolution transmission electron microscopy and (c) selected area electron diffraction images of nanocrystalline Zn doped PbS film.

Transmission electron microscopy (TEM) image of nanocrystalline $\mathrm{Zn}$ doped $\mathrm{PbS}$ thin films is shown in Fig.4. It reveals small particles attach together as well as large particles having spherical shapes. The particles in dark colour shown in Fig.4(a) are the nanocrystalline Zn doped $\mathrm{PbS}$ and the calculated particles size is found to be in the range of $8-10 \mathrm{~nm}$ which is in good agreement with the X-ray diffraction results. HRTEM is used to study the structure as well as to observe lattice images showing different orientations of the nanocrystals of $\mathrm{Zn}$ doped $\mathrm{PbS}$. The HRTEM image shown in Fig. 4(b) exhibits lattice fringes with d-spacing of $0.28 \mathrm{~nm}$ corresponding to the (200) reflection of the PbS cubic phase. Selected area electron diffraction (SAED) image shown in Fig.4(c) exhibits multiple diffractions rings with missing periodicity which is due to the random orientation of the particles.

\subsection{I-V characteristics of the Schottky barrier junction}

The prepared $\mathrm{Zn}$ doped $\mathrm{PbS}$ thin films is a p-type semiconductor as determined by the hot probe method. Gold electrode with a work function $4.08 \mathrm{eV}$ is deposited above the PbS films to form Schottky Barrier Junction between $\mathrm{Al}$ and $\mathrm{PbS}$ film. The reverse bias condition refers for $\mathrm{Al} /(\mathrm{p}) \mathrm{Mn}$ doped $\mathrm{PbS} / \mathrm{ITO}$ structure to a bias voltage across the junction with positive polarity connected to the $\mathrm{p}$ type $\mathrm{Zn}$ doped $\mathrm{PbS}$ film through ITO electrode making Ohmic contact at the back and negative polarity to counter electrode of barrier metal Al. Fig.5 shows the energy band diagram of a typical $\mathrm{Al} /(\mathrm{p}) \mathrm{Zn}$ doped $\mathrm{PbS}$ Schottky barrier junction before and after formation of the contact. 


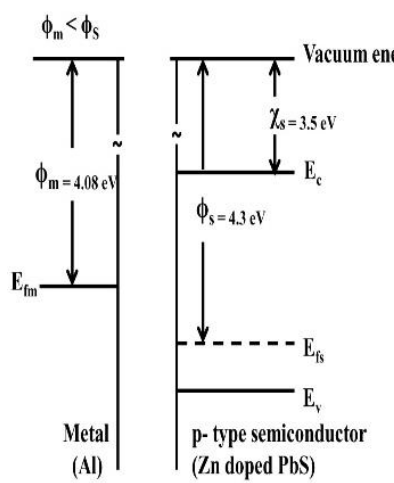

(a)

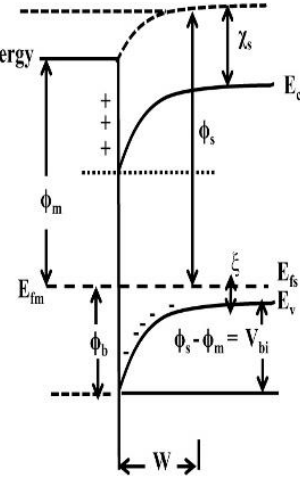

(b)

Fig. 5. Energy band diagram of Al/(p)Zn doped PbS Schottky Barrier Junction (a) before contact and (b) after contact.

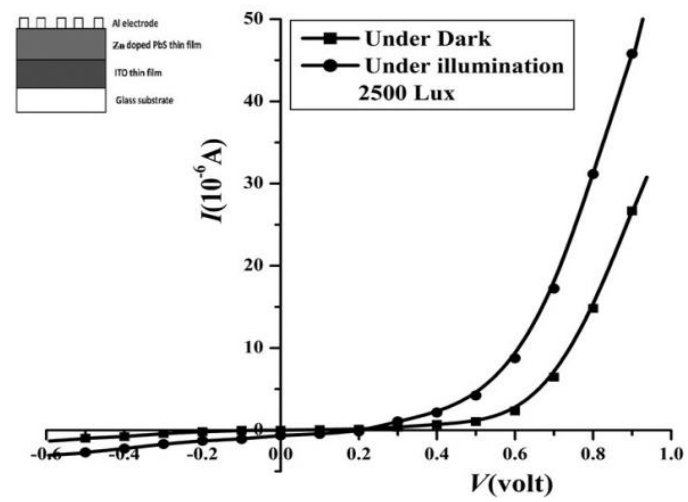

Fig. 6. I-V characteristics of a typical Al/(p) Zn doped PbS Schottky Barrier junction in dark and under illumination at room temperature (303K) and (inset) Schematic diagram of Al/(p)PbS Schottky barrier junction.

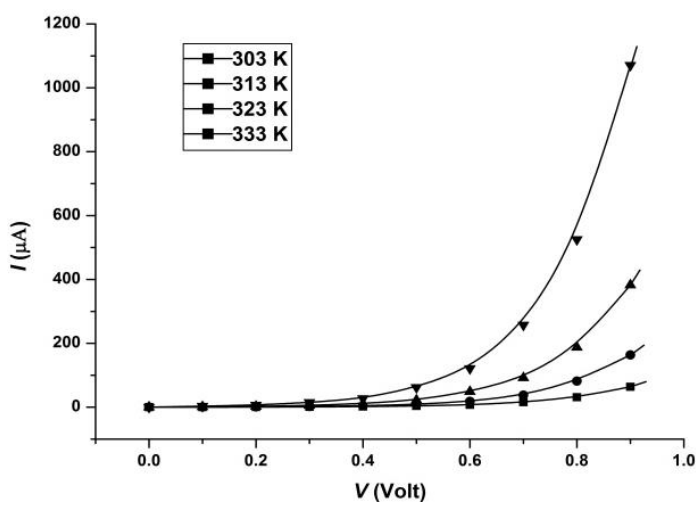

Fig. 7. I-V characteristics of Al/(p)PbS Schottky Barrier Junction in dark at various temperatures.

Fig. 6 shows the $I-V$ characteristics of the typical $\mathrm{Al} /(\mathrm{p}) \mathrm{Zn}$ doped $\mathrm{PbS}$ Schottky Barrier Junction in dark and under illumination at room temperature $(303 \mathrm{~K})$. The junction is formed to exhibit rectifying characteristics both in dark and under illumination (2500 lux). However, the characteristics under illumination shows photovoltaic effect and are more rectifying in nature. Fig. 7 shows the $I-V$ characteristics of the typical $\mathrm{Al} /(\mathrm{p}) \mathrm{PbS}$ Schottky Barrier Junction under dark at 
various temperatures. It has been observed that beyond room temperature $(303 \mathrm{~K})$, the current increases abruptly with voltage.

The non-linear forward bias current through a Schottky contact could be well described by the thermionic emission theory. According to thermionic emission theory, the current density in Schottky barrier diodes is given as

$$
J=J_{o} \exp \left(\frac{q V}{n k T}\right)\left[1-\exp \left(\frac{-q V}{k T}\right)\right]
$$

where $J_{o}$ is the saturation current density, $\mathrm{k}$ is the Boltzman constant, $\mathrm{n}$ is the ideality factor, $T$ is the absolute temperature, $q$ is the electron charge and $V$ is the applied voltage. The saturation current density $J_{o}$ can be written as

$$
J_{o}=A^{*} T^{2} \exp \left(\frac{-q \phi_{b}}{k T}\right)
$$

where $A^{*}$ is the effective Richardson constant and $\phi_{b}$ is the barrier height. The ideality factor (n) and the saturation current density $\left(J_{o}\right)$ of a Schottky diode is calculated from the slope of the linear region of the forward bias and the straight line intercept of Fig. 8 at $V=0$. The equation for $n$ can be expressed as

$$
n=\frac{q}{k T}\left[\frac{d V}{d\left(\ln \left(\frac{J}{1-e^{-q V / k T}}\right)\right)}\right]
$$

Fig. 8 shows the linear portions of the $\ln \left\{J /\left(1-e^{-q V / k T}\right)\right\}$ vs $V$ plots of the typical $\mathrm{Au} /(\mathrm{n}) \mathrm{PbS}$ Schotky Barrier Junction at different temperatures ranging from $303 \mathrm{~K}$ to $333 \mathrm{~K}$. The values of the saturation current density and ideality factor of the junctions at different temperatures are calculated from these plots and are given in Table 1.

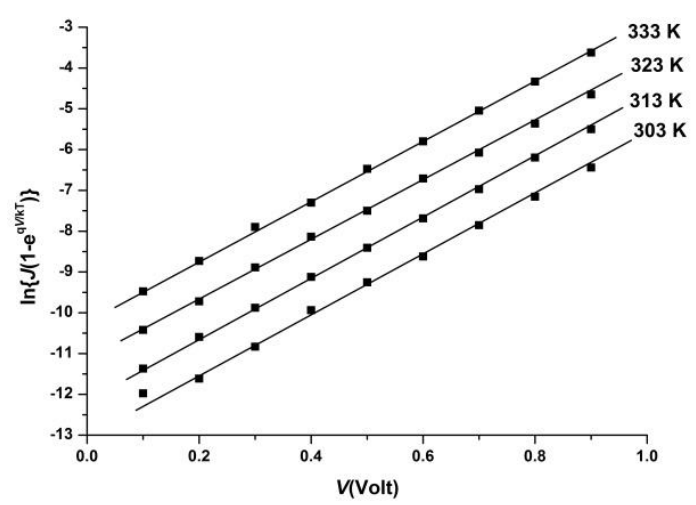

Fig. 8. $\ln \left\{J /\left(1-e^{-q V / k T}\right)\right\}$ versus V plots of the typical Al/(p)PbS Schottky Barrier Junction at different temperatures in dark. 


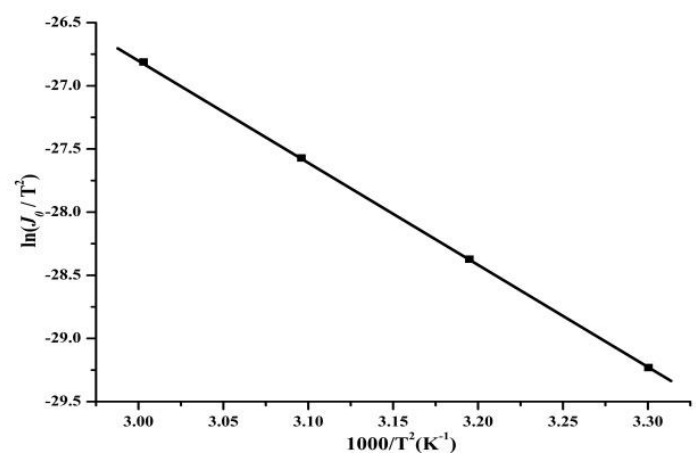

Fig. 9. In $\left(J_{d} / T^{2}\right)$ versus $T^{l}$ plots at different temperatures in dark of the typical $A l /(p) P b S$ Schottky Barrier Junction.

The ideality factor $(n)$ is observed to decrease while the saturation current density $J_{\mathrm{o}}$ is found to increase with increase of temperature for the typical junction. The increase in saturation current with temperature is due to the fact the the current transport mechanism is dominated by thermionic emission process (39). The calculated values of $J_{\mathrm{o}}$ at different temperatures are used to draw $\ln \left(J_{\mathrm{o}} / T^{2}\right)$ vs $\mathrm{T}^{-1}$ ( Richardson plot).

Fig. 9 shows such Richardson plot for the typical junction. Table 1 shows the calculated values of Richardson constant $\left(A^{*}\right)$ and barrier heights of the typical junction. The barrier heights measured from these Richardson plots are found to increase $0.749 \mathrm{eV}$ to $0.755 \mathrm{eV}$ for the typical $\mathrm{Al} /(\mathrm{p}) \mathrm{PbS}$ Schottky Barrier Junction. The increase in barrier heights with temperature is due to the inhomogeneous distribution of barrier heights at the metal semiconductor interface (40).

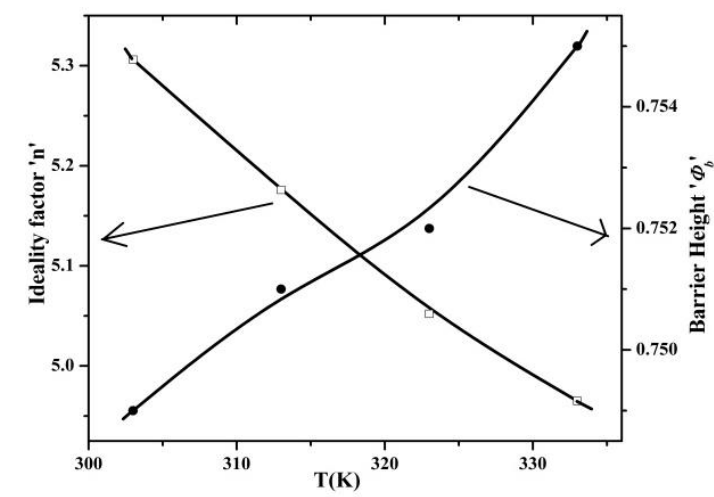

Fig. 10. Plots of Ideality factor (n), Schottky Barrier Height $\left(\phi_{b}\right)$ with temperature $(T)$ for the typical $A l /(p) P b S$ Schottky Barrier Junction (a) as-prepared and (b) after heat treatment.

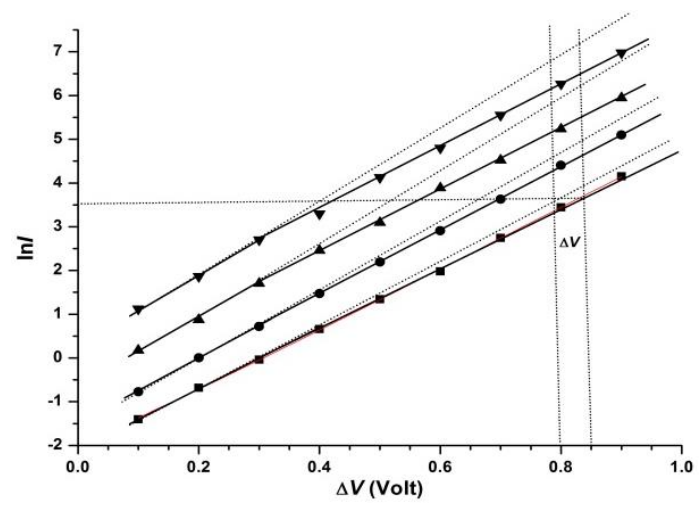

Fig. 11. Plot of lnI versus $V$ of $A l /(p) P b S$ Schottky barrier junction at different temperature. 
Fig. 10 shows temperature variation of the ideality factors (n), Schottky Barrier height $\left(\phi_{b}\right)$ for the typical junction as-prepared and after heat treatment. It is observed that the Barrier height $\left(\phi_{b}\right)$ increases with the increase of temperature while the diode ideality factor $(n)$ decreases with the increase of temperature.

From the study, it is observed that both the Saturation current density $\left(J_{o}\right)$ and the Barrier height $\left(\phi_{b}\right)$ increases with the increase of temperature while the diode ideality factor (n) decreases with the increase of temperature.

\subsection{Series resistance}

The Plot of $\ln I$ versus $V$ of $\mathrm{Al} /(\mathrm{p}) \mathrm{PbS}$ Schottky barrier junction at different temperatures deviate from the straight line as shown in Fig. 11 and this is due to the presence of series resistance $\left(R_{\mathrm{S}}\right)$ associated with the region between the depletion region and Ohmic contact. Here the voltage drop across $R_{s}$ causes the actual voltage developed across the barrier region to be less than the applied voltage to the junction. The values of $R_{s}$ obtained by plotting $\Delta V$ vs $I$ (as shown in Fig. 12) are given in Table 1 . The series resistances so obtained are found to be in the order of $\mathrm{K} \Omega$. The decrease in value of $R_{s}$ with increasing temperature is due to an increase in the number of free charge carriers by bond breaking [41].

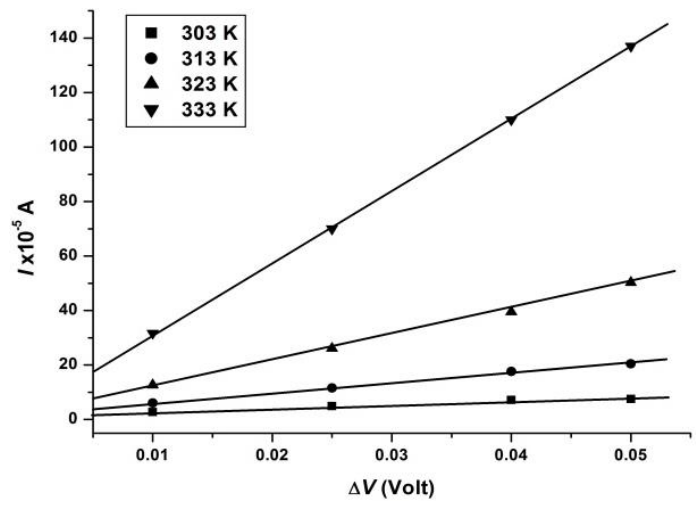

Fig. 12. Plot of I vs $\Delta V$ plots) of the typical $A l /(p) P b S$ Schottky barrier junction at different temperatures.

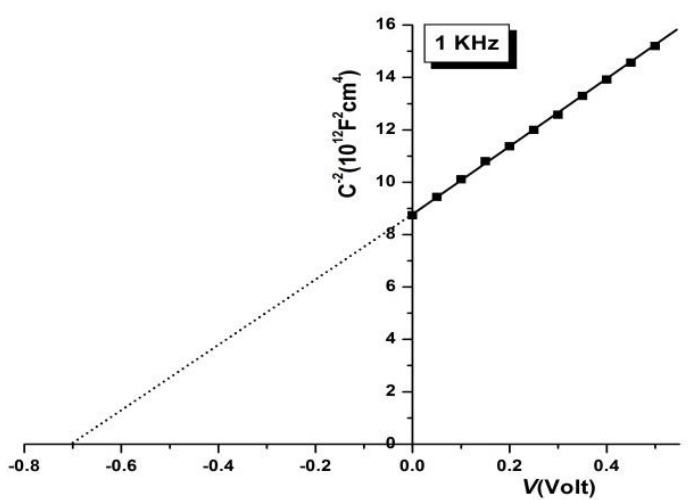

Fig.13. Plot of $C^{-2}$ versus $V$ for Al/(p)PbS Schottky Schottky barrier junction at room temperature $303 \mathrm{~K}$. 
Table 1. Junction parameters of $A l /(p) P b S$ junction at different temperatures.

\begin{tabular}{|c|c|c|c|c|c|c|}
\hline $\begin{array}{c}\text { Temperature } \\
(\mathrm{K})\end{array}$ & $\begin{array}{c}\text { Saturation } \\
\text { current density } \\
\mathrm{J}_{\mathrm{o}}\left(\mathrm{Acm}^{-2}\right)\end{array}$ & $\begin{array}{c}\text { Ideality } \\
\text { factor }(\mathrm{n})\end{array}$ & $\begin{array}{c}\text { Potential } \\
\text { barrier } \\
\text { height }\left(\phi_{\mathrm{b}}\right) \\
\mathrm{eV}\end{array}$ & $\begin{array}{c}\text { Series } \\
\text { resistance } \\
\mathrm{R}_{\mathrm{s}}(\Omega)\end{array}$ & $\begin{array}{c}\text { Carrier } \\
\text { concentration } \\
\left(\mathrm{N}_{\mathrm{a}}\right) \mathrm{cm}^{-3}\end{array}$ & $\begin{array}{c}\text { Richardson } \\
\text { Constant } \mathrm{A}^{*} \\
\left(\mathrm{Acm}^{-2} \mathrm{~K}^{-2}\right)\end{array}$ \\
\hline 303 & $2.831 \times 10^{-6}$ & 5.31 & 0.749 & 644 & \multirow{2}{*}{$6.65 \times 10^{16}$} & \multirow{2}{*}{86} \\
\hline 313 & $7,124 \times 10^{-6}$ & 5.18 & 0.751 & 242 & & \\
\hline 323 & $16.819 \times 10^{-6}$ & 5.05 & 0.752 & 87 & & \\
\hline 333 & $41.038 \times 10^{-6}$ & 4.47 & 0.755 & 36 & & \\
\hline
\end{tabular}

\section{6. $\mathrm{C}-\mathrm{V}$ characteristics of the Schottky barrier junction}

The reverse bias $C^{-2}$ versus $V$ plot of the $\mathrm{Al} /(\mathrm{p}) \mathrm{PbS}$ junction measured in the room temperature (303K) at a frequency of $1 \mathrm{KHz}$ is shown in Fig.13.

The depletion layer capacitance in Schottky barrier diod is expressed as [41]

$$
C=\left(\frac{q \varepsilon_{s} N_{a}}{2}\right)^{\frac{1}{2}}\left(V_{d}-\frac{k T}{q}\right)^{\frac{-1}{2}}
$$

where $\varepsilon_{\mathrm{s}}=160 \varepsilon_{\mathrm{o}}$ is the permittivity of the PbS [42], $\varepsilon_{\mathrm{o}}=8.854 \times 10^{-12}$ and $N_{a}=$ acceptor density or the carrier concentration. Since, the diffusion potential, $V_{d}=V_{b i}+V_{r}$, where $V_{b i}$ is the diffusion potential at zero bias, the above expression for $C$ may be written as

$$
\begin{gathered}
C=\left(\frac{q \varepsilon_{s} N_{a}}{2}\right)^{\frac{1}{2}}\left(V_{b i}+V_{r}-\frac{k T}{q}\right)^{\frac{-1}{2}} \\
\frac{1}{C^{2}}=\frac{2\left(V_{b i}+V_{r}-\frac{k T}{q}\right)}{q \varepsilon_{s} N_{a}} \\
d\left(\frac{1}{C^{2}}\right)=d\left(C^{-2}\right)=\frac{2 d\left(V_{r}\right)}{q \varepsilon_{s} N_{a}} \\
N_{a}=\frac{2 d\left(V_{r}\right)}{q \varepsilon_{s} d\left(C^{-2}\right)}
\end{gathered}
$$

The plot of $C^{-2}$ versus $V$, according to equation (9) will give a straight line with a

$$
\text { Slope }=\frac{2}{q \varepsilon_{s} N_{a}}
$$

From eqn. (8), at $C^{-2}=0$, the intercept is

$$
V_{i}=-V_{r}=V_{b i}-\frac{k T}{q}
$$




$$
V_{b i}=V_{i}+\frac{k T}{q}
$$

The diffusion potential, $V_{b i}$ is determined by knowing $V_{i}$ from the plot (Fig.13) and found to be $0.706 \mathrm{eV}$. The carrier concentration $N_{a}$ obtained by using (10) is $6.65 \times 10^{16} / \mathrm{cm}^{3}$. As the barrier height $\phi_{b}$ is the sum of the diffusion potential $V_{b i}$ and $\xi$, this can be calculated from the equations

$$
\begin{aligned}
& \xi=\frac{k T}{q} \ln \left(\frac{N_{c}}{N_{d}}\right) \\
& \phi_{b}=V_{i}+\xi+\frac{k T}{q}
\end{aligned}
$$

where $N_{c}=2\left(2 \pi m_{e}{ }^{*} \frac{k T}{h^{2}}\right)^{\frac{3}{2}}$ is the effective density of states in the conduction band for $\mathrm{PbS}$ at room temperature, $N_{d}$ is the doping concentration calculated from the slopes of $C^{-2}-V$ plots (Fig. 13), $h$ is the Planck's constant, $k$ is the Boltzmann's constant and $m_{e}^{*}$ is the effective electron mass for $\mathrm{PbS}$ given by $m_{e}^{*}=0.080 m_{o}$ where $m_{o}$ is the rest mass of electron [43]. Thus, the barrier height $\phi_{b}$ obtained from the $\mathrm{C}-\mathrm{V}$ plot is $0.77 \mathrm{eV}$. The barrier height $\phi_{b}$ obtained from I- $\mathrm{V}$ measurements at room temperature is 0.75 which is lower than those obtained from $\mathrm{C}-\mathrm{V}$ measurements. The difference may be due to the formation of an interfacial layer containing defects. Thus, interfacial capacitance and capacitance due to depletion layer are in series, thereby decreasing the total capacitance and as a result, $\mathrm{C}^{-2}$ increases. This increases the intercept of $\mathrm{C}^{-2}$ versus $\mathrm{V}$ plot and increases the barrier height which may be due to the transport mechanism in these diodes and it is ot purely thermionic emission in nature. Another reason may be the lowering of barrier height by the image force due to current flow across the barrier. In view of the fact that the I-V method involves the flow of electrons from semiconductor to the metal, the barrier height determined from the I-V method will logically yield lower barrier heights than the C-V measurements [44].

\section{Conclusions}

Nanocrystalline Mn doped PbS thin film is prepared and deposited on ITO glass substrate by $\mathrm{CBD}$ method and $\mathrm{Au} /(\mathrm{n}) \mathrm{Mn}$ doped $\mathrm{PbS}$ Schottky Barrier junction is fabricated using $\mathrm{Au}$ electrode deposited by vacuum evaporation over the Mn doped PbS film on ITO glass substrate. SEM results reveal that the overall surface morphology of the film is fairly smooth and uniform. The films consist of particles of different shapes and sizes. The particle size determined from XRD and TEM are closely agreed. The current-voltage characteristics of the junction at different temperatures are investigated. The ideality factor decreases and the potential barrier height increases with increase in temperature. These observations have been ascribed to barrier in homogeneities at the metal-semiconductor interface. The calculated series resistance $\mathrm{R}_{\mathrm{s}}$ at different temperature is found to be in the range from $644 \Omega$ to $36 \Omega$. The value of $R_{s}$ decreases with increasing temperature due to increase in the number or density of free charge carriers by bond breaking. The barrier height determined from the $\mathrm{C}-\mathrm{V}$ is larger than those obtained from I-V characteristics. The carrier concentration $\mathrm{N}_{\mathrm{a}}$ obtained from the $\mathrm{C}-\mathrm{V}$ is found to be in the order of $10^{16} / \mathrm{cm}^{3}$. 


\section{Acknowledgments}

I express my gratitude to IIT. Guwahati, India for EDX analysis, Department of Physics, Manipur University, Manipur, India, Department of instrumentation \& USIC,Gauhati University, Guwahati, India for providing XRD, SEM and lastly SAIF, NEHU, Shillong, India for TEM analysis.

\section{References}

[1] L. Rajen Singh, Chalcogenide Letters 15(1), 15 (2019); https://doi.org/10.1201/9780429027611-1

[2] Yu-Zung Chiou, Yan-Kuin Su, Shoou-Jinn Chang, Jone F. Chen, Chia-Sheng, Chan Sen Hai Liu, Yi-Chao Lin, Chin-Hsiang Chen, Jpn. J. Appl. Phys. 41, 3643 (2002).

[3] T. Tsutomu, O. Shigeki, K. Kazuo, F.Junji, Jpn. J. Appl. Phys. Pt. 24, 593 (1985).

[4] Chen, C. H. Chang, S. J. Su, Y. K. Chi, G. C. Chi, J. Y. Chang, C. A. Sheu, J. K. Chen, Photonics Technology Letters IEEE 13, 848 (2001).

[5] F. D. Shepherd, A. C. Yang Jr., International Electron Devices Meeting 19, 310 (1973).

[6] Chih-Tangn Sah, Fundamentals of Solid State Electronics, World Scientific (Electronicbookwww.worldscincebook.com) (1991).

[7] Boylestad Nashelsky, Electronic Devices and Circuit Theory, Pentice Hallof India, New Delhi, 2003.

[8] M. Navaneethan, K. D. Nisha, S. Ponnusamy, C. Muthamizhchelvan, Rev. Adv. Mater.Sci. 21, 217 (2009).

[9] N. B. Kotadiya,A. J. Kothari, D. Tiwari, T. K. Chaudhuri, Appl. Phys. A 108, 819 (2012); https://doi.org/10.1007/s00339-012-6974-7

[10] B. Thangaraju, P. Kaliannan, Semiconductor Science and Technology 15, 849 (2000); https://doi.org/10.1088/0268-1242/15/8/311

[11] P. Raji, C. Sanjeeviraja, K. Ramchandran, Bull. Mater. Sc. 28(3), 233 (2005); https://doi.org/10.1007/BF02711253

[12] R. Sahraei, R.Shahriyar, S.Majles, M. H. Ara, A. Daneshfar, N. Shokri, Prog. Colour colourants Coat. 3, 82 (2010).

[13] Gary Hodes, Chemical Solution Deposition of Semiconductor Films, Marcel Dekker, Inc. 2002; https://doi.org/10.1201/9780203909096

[14] S. Mageswari, L. Dhivya, B. Planivel, R.Murugan, Journal of Alloys and Compounds 545, 41 (2012); https://doi.org/10.1016/j.jallcom.2012.08.010

[15] R. K. Joshi, A. Kanjilal, H. K. Sehgal, Nanotechnology 14, 809 (2004);

https://doi.org/10.1088/0957-4484/14/7/320

[16] N. F. Mott, E. A. Davis, Electronics Processes in Non-Crystalline Materials, Clarendon, Oxford, 428 (1979).

[17] V. I. Levchenko, L. I. Postnova, V. P. Bondarenko, N. N. Vorozov, V. A. Yakovtseva,L. N. Dolgyi, Thin solid films 348, 141 (1999); https://doi.org/10.1016/S0040-6090(99)00052-8

[18] S. Seghaier, N. Kamoun, R. Brini, A. B. Amara, Mater. Chem. Physics. 97, 71 (2006); https://doi.org/10.1016/j.matchemphys.2005.07.061

[19] J. J. V. Jauregu, R. R. Bon, A. M. Galvan, M. S. Lerma, Thin Solid Films 441, 104 (2003); https://doi.org/10.1016/S0040-6090(03)00908-8

[20] E. Pentia, L. Pintillie, C. Tivarus, I. Pintillie, T. Botila, Mater. Sci. Eng. B 80, 23 (2001); https://doi.org/10.1016/S0921-5107(00)00578-X

[21] R. K. Joshi, A. Kanjilal, H. K. Sehgal, Appl. Surf. Sci. 221, 43 (2004);

https://doi.org/10.1016/S0169-4332(03)00955-3

[22] K. M. Gadave, S. A. Jodgudri, C. D. Lokhande, Thin Solid Films 245, 7 (1994); 
https://doi.org/10.1016/0040-6090(94)90869-9

[23] S. Bhushan, M. Mukharjee, P. Bose, J. Mater. Sci. Mater. Electron. 13, 581(2002);

https://doi.org/10.1023/A:1020196030287

[24] E. H. Rhoderick, R. H. Williams, Metal-Semiconductor Contacts, Clarendon Press, Oxford University Press, Oxford, 1988.

[25] H. Cetin, E. Ayyildiz, Semiconductor. Sci. Technology 20, 625 (2005);

https://doi.org/10.1088/0268-1242/20/6/025

[26] R. L. Van Meirhaeghe, W. H. Laflere, F. Cardon, J. Appl.Physics. 76, 403 (1994);

https://doi.org/10.1063/1.357089

[27] E. Gur, S. Tuzeman, B. Kilic, C. Coskun, J. Phys. Condens. Matter. 19, 196 (2007).

[28] Jason P. Clifford, K. W. Johnston, L. Levina, E. H. Sargent, Appl. Phys. Lett. 91,253117

(2007); https://doi.org/10.1063/1.2823582

[29] R. Debnath, J. Tang, D. Aaron Barkhouse, Xihua Wang, A. G. Pattantyus-Abraham, L.

Brzozowski, L, Levina, E. Sargent, Amer.Chem. J. 132, 5952 (2010);

https://doi.org/10.1021/ja1013695

[30] D. David Strasfeld, A. Dorn, D. D. Wanger, G. Moungi Bawendi, Nano.Lett. 12, 569 (2012); https://doi.org/10.1021/nl204116b

[31] Powder Diffract. File, JCPDS Internat. Centre Diffract. Data, PA 19073-3273, U.S.A., 2001.

[32] K. M. Gadave, S. A. Jodgudri, C. D. Lokhande, Thin Solid Films 245, 7 (1994);

https://doi.org/10.1016/0040-6090(94)90869-9

[33] J. Puiso, S. Tamulevicius, G. Laukaitis, S. Lindross, M. Leskeia, V. Snitka, Thin Solid Films 403, 457 (2002); https://doi.org/10.1016/S0040-6090(01)01662-5

[34] B. D. Cullity, Elements of X-ray Difrraction, Massachusetts: Addison-Wesley, 102 (1956).

[35] Juan Chu, Zhengguo Jin, Shu Cai, Jingxia Yang, Zhanglian Hong, Thin Solid Films 520,182 (2012); https://doi.org/10.1016/j.tsf.2011.08.101

[36] R. Sahraei, S. Shahriyar, M. H. Majles Ara, A. Daneshfar, N. Shokri, Prog. Color Colorants Coat. 3, 82 (2010).

[37] S. Prabahar, M. Dhanam, Journal Crystal Growth 285, 41 (2005);

https://doi.org/10.1016/j.jcrysgro.2005.08.008

[38] S. Mageswari, L. Dhivya, B. Palanivel, R. Murugan, Journal of Alloys and Compounds 545,

41 (2012); https://doi.org/10.1016/j.jallcom.2012.08.010

[39] S. M. Sze, Physics of Semiconductor Devices, 2nd Edn, Willey Eastern Ltd, New Delhi, 251 (1986).

[40] A. Ahaitouf, H. Srour, S. Ould Saad Hamady, N. Fressengeas, A. Ougazzaden, J. A.

Salvestrini, Thin Solid Films 522, 345 (2012); https://doi.org/10.1016/j.tsf.2012.08.029

[41] V. Janardham, H. K. Lee, K. H. Shim, H. B. Hong, S. H. Lee, K. H. Ahn, C. J. Choi, J. Alloys Compd. 504, 146 (2010); https://doi.org/10.1016/j.jallcom.2010.05.074

[42] A. A. Qidwai, Journal of Engineering and Sciences, July-December, 8 (2010).

[43] T. Torimoto, H. Uchid, T. Sakata, H.Mori, H. Yoneyama, J. American Chem. Soc. 115, 1874 (1993); https://doi.org/10.1021/ja00058a036

[44] V. L. Devi, I. Jyothi, V. R. Reddy, C. Choi, The Open Applied Physics Journal 5, 1 (2012). 